\title{
Creep Behavior of a Zirconium Alloy Processed by Equal-Channel Angular Pressing
}

\author{
V. Sklenicka ${ }^{a, *}$, J. Dvorak ${ }^{a}$, P. Kral ${ }^{a}$, M. Svoboda ${ }^{a}$, M. Kvapilova $^{a}$, V.I. Kopylov ${ }^{b}$ \\ S.A. NiKULin ${ }^{c}$ and S.V. DObatKin ${ }^{c, d}$ \\ ${ }^{a}$ Institute of Physics of Materials, Academy of Sciences of the Czech Republic \\ Zizkova 22, 61662 Brno, Czech Republic \\ ${ }^{b}$ Physico-Technical Institute of NAS Belarus, Kuprevicha 10, 220141 Minsk, Belarus \\ ${ }^{c}$ National University of Science and Technology "MISIS", Leninskiy prospect 4, 119049 Moscow, Russia \\ ${ }^{d}$ A.A. Baikov Institute of Metallurgy and Materials Science of RAS \\ Leninskiy prospect 49, 119991 Moscow, Russia
}

\begin{abstract}
A $\mathrm{Zr}-2.5 \mathrm{wt} \% \mathrm{Nb}$ alloy was processed by equal-channel angular pressing and then tested under creep conditions at $623 \mathrm{~K}$ using a tensile stress within the range from 120 to $300 \mathrm{MPa}$. The results show conventional power-law creep with a stress exponent of $n>3$ which is consistent with an intragranular dislocation process involving the glide and climb of dislocations. It is demonstrated that diffusion creep is not important in these tests. For comparison purposes, the experiments were conducted using both the unprocessed alloy and after processing by equal-channel angular pressing. It was found that under same testing conditions the measured minimum creep rates in the pressed alloy with ultrafine grain sizes were faster than in the same alloy in a coarse-grained unprocessed condition.
\end{abstract}

PACS: 81.40.Lm, 62.20.Hg, 81.05.-t, 81.07.Bc, 81.70.Bt

\section{Introduction}

During the last two decades, equal-channel angular pressing (ECAP) has emerged as a widely-known procedure for the fabrication of ultrafine-grained (UFG) metals and alloys [1]. The significance of ECAP technique for producing ultrafine-grained materials can be evaluated by two criteria: (i) the capability of producing unique structures for fundamental studies, and (ii) the possibility of scaling up for economical industrial applications [2].

Research on the $\mathrm{Zr}-2.5 \mathrm{wt} \% \mathrm{Nb}$ alloy can meet both of above criteria. Very recently the static and fatigue strength properties at ambient temperature of the $\mathrm{Zr}-2.5 \mathrm{wt} \% \mathrm{Nb}$ alloy have been reported after ECAP pressing [3]. It was shown that the formation of UFG structure produced by ECAP led to significant strengthening, increase of the lifetime in a high stress amplitude range and increase of the fatigue strength to those typical of coarse-grained state. As possible material for bio-implants, the $\mathrm{Zr}-2.5 \mathrm{wt} \% \mathrm{Nb}$ alloy provides excellent biocompatibility. Zirconium-niobium alloys which are widely used in the nuclear industry especially as cladding tubes, grid spacers and guide tubes for pressurized water reactors, can present a variability of their creep behavior

* corresponding author; e-mail: sklen@ipm.cz as a function not only of the chemical composition but also of the microstructure. Unfortunately, only limited reports are available describing the creep behavior of zirconium based alloys and no creep data are available for these alloys subjected to ECAP processing.

Although the grain size is not normally thought to affect creep behavior in most theories of dislocation creep, the ultrafine grain sizes of zirconium alloy processed by ECAP may represent a substantial grain boundary area which exerts on the creep resistance by influencing the dislocation structure in modifying the rates of generation and annihilation of dislocations and this may cause a higher creep rate. Further, at the water reactor operating temperature (523-623 K) of the cladding tubes and at low applied stresses Nabarro-Herring [4, 5] or Coble [6] diffusion creep dependent on grain size may be considered as the possible rate controlling mechanism in $\mathrm{Zr}-\mathrm{Nb}$ alloys [7-12]. Thus, this work was initiated to provide further information on mechanism(s) of creep flow and the link between structure and creep in the $\mathrm{Zr}-2.5 \mathrm{wt} \% \mathrm{Nb}$ alloy processed by ECAP.

\section{Material and experimental procedures}

The experiments were conducted using the same $\mathrm{Zr}-2.5$ wt\% Nb alloy (alloy E125 in Russian standard, containing in wt\%: $97.25 \mathrm{Zr}, 2.7 \mathrm{Nb}, 0.05 \mathrm{Fe}$ ) as was used 
in an earlier report which described its fatigue properties [3]. After cold rolling and annealing at $803 \mathrm{~K}$ for $1 \mathrm{~h}$ the structure of the alloy was partially polygonized and partially recrystallized. Billets of the unprocessed alloy were pressed by ECAP at a temperature of $693 \mathrm{~K}$ with a die having an internal angle of $90^{\circ}$ between two parts of the channel by the route close to $B_{\mathrm{C}}$ [3]. The pressing was repeated up to a total of 6 ECAP passes giving a true (logarithmic) strain of 6.5 [3]. The processing route $B_{\mathrm{C}}$ was used because it led most effectively to an array of equiaxed grains. A detailed description of the material procedure was given in an earlier report [3].

Creep tests were conducted in tension using flat samples having gauge lengths of $25 \mathrm{~mm}$ and cross-sectional areas of $3.0 \mathrm{~mm} \times 3.2 \mathrm{~mm}$. For comparison reasons, creep tests were performed on both the unprocessed state and the state after ECAP pressing at a temperature of $623 \mathrm{~K}$ using an applied stress within the range from 120 to $300 \mathrm{MPa}$. True strain-time readings were continuously recorded by the PC-based data acquisition system. Following ECAP and creep testing, microstructure development was characterized and analysed using transmission and scanning electron microscopy.

\section{Experimental results}

\subsection{Creep behavior in the unprocessed alloy and after processing by ECAP}

Representative creep curves are shown in Fig. 1. All of these plots were obtained at an absolute temperature, $T$, of $623 \mathrm{~K}$, using an applied stress, $\sigma$, of $300 \mathrm{MPa}$ and they show (a) the variation of the strain, $\varepsilon$, with the time, $t$, (b) the variation of the strain rate, $\dot{\varepsilon}$, with the time and (c) the variation of the strain rate with the strain.

Several important conclusions may be reached from inspection of these data. First, it is important to note that there is no difference in the fracture strain levels so that the total strains of $\approx 0.25$ achieved in the pressed samples pulled out to failure are practically the same as the fracture strain achieved in the unprocessed alloy (Fig. 1a). Second, the unprocessed material exhibits markedly longer creep life or markedly longer duration of creep exposure than the ECAP material (Fig. 1b). Third, the minimum creep rate for the unprocessed material is about one order of magnitude lower than that of the ECAP alloy (Fig. 1c). Let us note that the difference in the minimum creep rate for the ECAP material and unprocessed alloy consistently increases with increasing number of ECAP passes.

The creep curves are somewhat different in appearance between the unprocessed and the processed alloy as illustrated in Fig. 1b. Apparently there is only a quasi-secondary stage in the unprocessed alloy and a little more than an abrupt minimum in the curves of strain rate versus time followed by rapid acceleration to final failure in the processed one. When the steady-state disappears, it is still possible to define the minimum creep

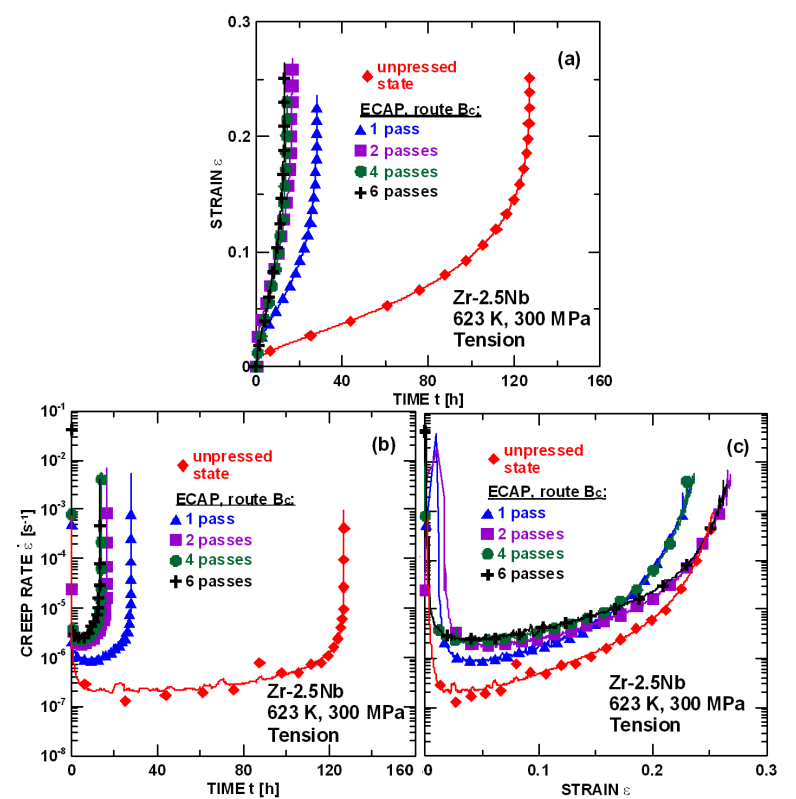

Fig. 1. Creep results for the unprocessed alloy and for samples processed by different number of ECAP passes showing: (a) creep curves of strain versus time, (b) the variation of creep rate with time and (c) the variation of creep rate with strain.

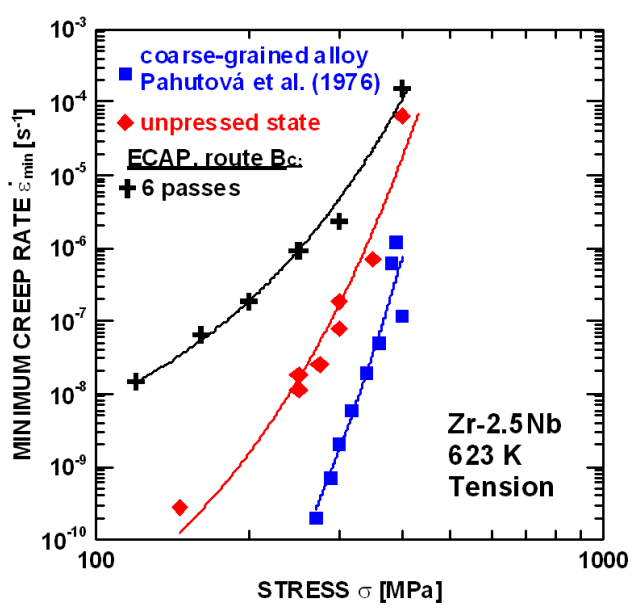

Fig. 2. Minimum creep rate versus stress for the unprocessed sample and for samples processed by 6 ECAP passes and the stress dependence of $\dot{\varepsilon}_{\text {min }}$ for an extremely coarse-grained $\mathrm{Zr}-2.5$ wt\% $\mathrm{Nb}$ alloys $(d \approx$ $300 \mu \mathrm{m})$ reported by Pahutová et al. [8].

rate $\dot{\varepsilon}_{\min }[13]$. Further differences are easily demonstrated by logarithmically plotting the minimum creep rate, $\dot{\varepsilon}_{\min }$, against stress, $\sigma$, as it is shown in Fig. 2 for the tests conducted at a temperature of $623 \mathrm{~K}$. Thus, the unprocessed material exhibits better creep resistance by comparison with the processed alloy. Furthermore, both states of the alloy exhibit similar trends in these plots: the values of the stress exponent of the creep rate, $n$, defined as $n=\left(\partial \ln \dot{\varepsilon}_{\min } / \partial \ln \sigma\right)_{\mathrm{T}}$ gradually increase with 
increasing stress. Figure 2 shows the experimental data reported by Pahutová et al. [8] on an extremely coarse-grained $\mathrm{Zr}-2.5 \mathrm{wt} \% \mathrm{Nb}$ alloy with an average grain size of $\approx 0.3 \mathrm{~mm}$.

\subsection{Microstructure observations}

Details of microstructure of the $\mathrm{Zr}-2.5 \mathrm{wt} \% \mathrm{Nb}$ alloy in as-received state and after ECAP are provided elsewhere [3], and therefore only a brief description is included here. Before ECAP, the alloy exhibits a mixed structure of the $\alpha$-Zr phase, which is partially polygonized with subgrain size of $\approx 700 \mathrm{~nm}$, and partially recrystallized with grain size of $1-5 \mu \mathrm{m}$. The $\alpha$-Zr phase is a hexagonal close-packed (hcp) phase containing up to $0.6 \mathrm{wt} \%$ niobium. Further, due to the low solubility of niobium in zirconium at low temperature the microstructure of the alloy contains boundary particles of the $\beta$-Nb body centred cubic phase of $10-50 \mathrm{~nm}$ and very few particles of $\beta-\mathrm{Zr}$ phase located predominantly inside the $\alpha$-Zr grains. The mostly ultrafine-grained microstructure of the $\mathrm{Zr}-2.5 \mathrm{wt} \% \mathrm{Nb}$ alloy after ECAP is somewhat oriented as a consequence of the formation of elongated subgrains separated by low-angle boundaries at the stage of unsteady polygonization [3] and/or shear bands at the early stages of ECAP. The transformation of the oriented subgrain structure into equiaxed grain structure occurs by the intersection of two systems of structure elements or by the formation of dislocation bridges in the oriented structure elements and by the subsequent coalescence and "rounding" of subgrains [3]. The grain size of ECAP material has not been thoroughly investigated owing to a limited resolution in characterization of

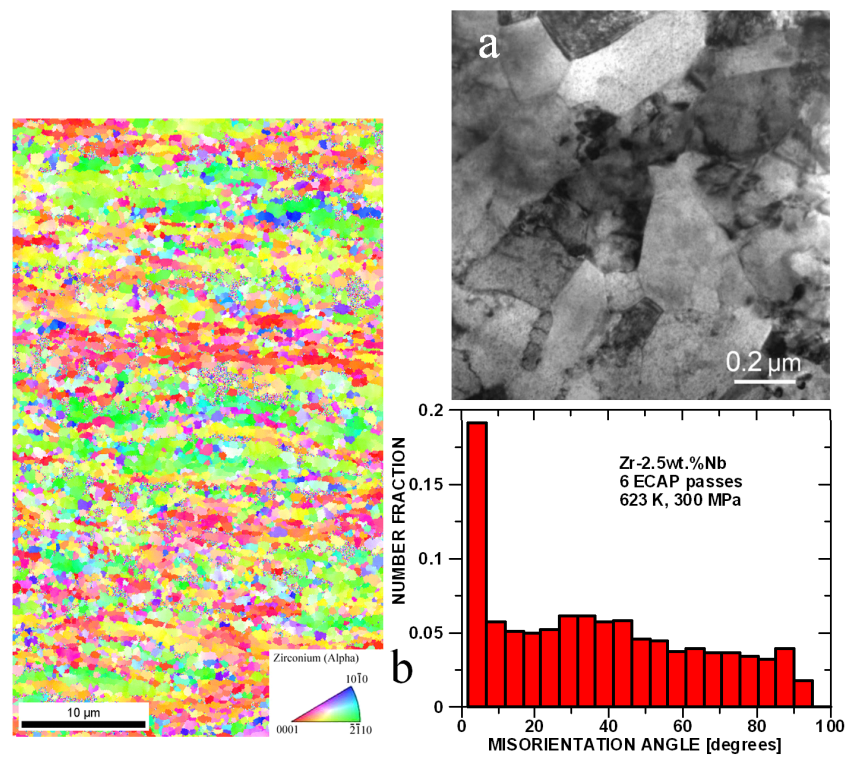

Fig. 3. Examples of microstructure of the $\mathrm{Zr}-2.5 \mathrm{wt} \% \mathrm{Nb}$ alloy after 6 ECAP passes and creep testing at $623 \mathrm{~K}$ and $300 \mathrm{MPa}$ (a) TEM micrograph and (b) an as-measured EBSD map and misorientation angle distribution of grain boundaries. very small grains using the electron backscatter diffraction (EBSD) method. However, again a mixed structure was observed with grain size of $\approx 500 \mathrm{~nm}$.

After creep exposures at $623 \mathrm{~K}$ small microstructural changes have been observed such as an increase of the size of $\alpha$-phase grains due to local dynamic recrystallization which took place to a limited extent during creep. The subgrains developed during ECAP formed isolated groups mutually separated by regions of $\alpha$-phase grains (Fig. 3a). Figure 3b shows as-measured EBSD map and misorientation angle distribution in the $\mathrm{Zr}-2.5 \mathrm{wt} \% \mathrm{Nb}$ alloy processed by ECAP and crept at $623 \mathrm{~K}$ and $300 \mathrm{MPa}$. No substantial difference in the relative fractions of high-angle $\left(\theta>15^{\circ}\right)$ grain boundary population was found among samples ECAP processed by 6 passes and crept at different stresses. These fractions were slightly increased during creep exposure up to an average value $\approx 75 \%$ for 6 ECAP passes.

\section{Discussion}

In polycrystalline materials, plastic deformation may generally occur by intragranular dislocation activity, grain boundary sliding or diffusion creep. Under steady-state conditions, the creep rate, $\dot{\varepsilon}$, varies with the applied stress, $\sigma$, the absolute temperature, $T$, and grain size, $d$, through a relationship of the form

$$
\dot{\varepsilon}=A D G b / k T(b / d)^{p}(\sigma / G)^{n},
$$

where $A$ is a dimensionless constant, $D$ - the appropriate diffusion coefficient, $G$ - the shear modulus, $b-$ the magnitude of the Burgers vector, $k$ - Boltzmann's constant, and $p$ and $n$ are exponents of the inverse grain size and the stress. Over a wide range of intermediate stresses the creep rate is controlled by intragranular process so that $p=0$ and there is no dependence on grain size, but at low stresses diffusion and intergranular creep processes [13] may become important, such as NabarroHerring [4, 5] and Coble [6] diffusion creep and/or grain boundary sliding [14], and this introduces a dependence on grain size with $p>1$.

The rate controlling creep deformation mechanism in $\mathrm{Zr}-\mathrm{Nb}$ alloys has not yet been unambiguously identified. In part, the difficulty in identifying the rate controlling mechanism arose from the significant variations in the reported values of the flow stress and the stress exponent, $n$, for nominally identical material. However, recent detailed studies have demonstrated that the discrepancy in data can also be a consequence of small variations of impurity levels [15].

In order to present creep data using Eq. (1), Fig. 4 shows a double logarithmic plot of the minimum creep rate versus the applied stress with experimental datum points plotted both for the processed alloy and for the tests conducted on the unprocessed alloy using the data from Fig. 2. The lines in Fig. 4 denote the predictions for different models of diffusion creep.

We will start discussion with the values of the stress exponent $n$. The data for the unprocessed alloy suggest 


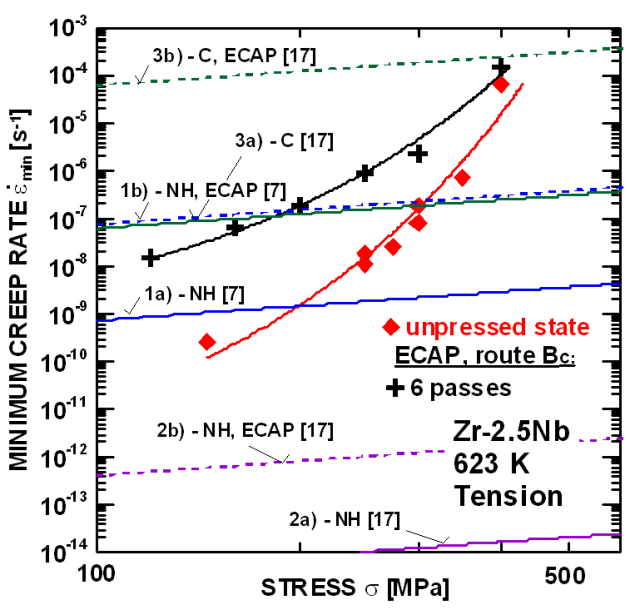

Fig. 4. The predicted minimum creep rates for the Nabarro-Herring ( $\mathrm{NH})$ and Coble $(\mathrm{C})$ diffusion creep. The broken lines denote the prediction for the ECAP processed material. Diffusion data for computations of NH creep rates were taken from different reports [7] and [17].

a value of $n$ close to $\approx 6$ whereas the processed alloy exhibits a value of $\approx 4$ for the lowest stresses and the stress exponent $n$ increases with increasing stress. The values of $n \approx 22$ for the unprocessed alloy and $n \approx 12$ for processed one are observed at the highest stress levels. In order to understand these results, it is necessary to look in more detail at the possible operating deformation mechanism(s).

Generally, high temperature climb of dislocations is associated with the stress exponents of $4-7$. However, it is also known that a stress exponent of $\approx 7$ may be a characteristic of a low temperature dislocation-climb controlled mechanism which requires an activation energy for dislocation core diffusion [10]. But in the literature frequently reported values of the measured creep activation energy are consistent with that of the lattice self-diffusion. Further, referring to Lagneborg's creep model of precipitation strengthened alloys [16] a gradual increase of the stress exponent $n$ may be due to an overlapping of the stress intervals characteristic for the dislocation climb and the Orowan mechanism. At the highest stress region creep rates become higher than is expected from power-law creep. These data are close to the power-law breakdown regime and the transition from power-law dependence to an exponential dependence of stress occurs. At $300 \mathrm{MPa}$ no substantial difference in the values of the minimum creep rate $\left(\dot{\varepsilon}_{\min } \approx 10^{-4} \mathrm{~s}^{-1}\right)$ between both the states of the alloy was found. For such high creep rates a significant contribution of an athermal deformation mechanism was suggested by Pahutová et al. [8].

In order to understand the creep behavior of the $\mathrm{Zr}-2.5 \mathrm{wt} \% \mathrm{Nb}$ alloy at lower stress, it is necessary to look in more detail at possible diffusion deformation mechanisms. Taking the grain size after $\mathrm{ECAP} \approx 0.5 \mu \mathrm{m}$ and $d \approx 5 \mu \mathrm{m}$ for unprocessed alloy, Fig. 4 denotes the predictions for the Nabarro-Herring [4, 5] and Coble [6] diffusion creep where $n=1$ and the values of $p$ are either 2 or 3 , respectively. The apparent inconsistency in two predictions for the Nabarro-Herring creep can be readily explained by the calculations using different values of grain boundary diffusion coefficient found in the literature. It should be noted that there are conflicting reports on grain boundary diffusivity in ultrafine-grained materials produced by severe plastic deformation: while several studies have reported anomalously high diffusivities, in other works the measured grain boundary diffusivities were consistent with the known data for coarse-grained materials [18]. No measurement of grain boundary diffusivity of UFG zirconium and its alloys has been available at present. Even for a simple nominally pure coarse-grained metal such as copper, the grain boundary coefficient varies by one order of magnitude. Therefore, using known diffusion coefficients, the theoretical and experimental creep rates may be in agreement only within an order of magnitude [19].

In Fig. 4 the lower lines for the Nabarro-Herring creep (lines $1 \mathrm{a}$ and $1 \mathrm{~b}$ ) demonstrate that this process is too slow to have any significant influence on the creep behavior of the alloy. By contrast, the upper lines for the Nabarro-Herring creep (lines $2 \mathrm{a}$ and $2 \mathrm{~b}$ ) and the lines for the Coble creep (lines $3 \mathrm{a}$ and $3 \mathrm{~b}$ ) suggest that these mechanisms may play some role in the creep behavior of the alloy at extremely low stresses. However, the experimentally determined high values $n \gg 1$ are not consistent with the occurrence of diffusion creep under creep testing conditions investigated in this work.

\section{Conclusions}

The important conclusion from creep experiments on the unprocessed and ECAP processed $\mathrm{Zr}-2.5 \mathrm{wt} \% \mathrm{Nb}$ alloy is that it is not necessary to invoke any new and different creep mechanism(s) in ECAP processed alloy in addition to and apart from dislocation mechanism and, therefore, it provides further confirmation that conventional creep mechanisms, already developed for coarse-grained materials, may be used to explain the flow characteristics of materials processed by ECAP [20-23]. The results show conventional power-law creep occurring in the processed specimens through a conventional intragranular process involving the glide and climb of dislocations. However, the creep resistance of the pressed alloy is distinctly lower at $623 \mathrm{~K}$ than the creep resistance of the unprocessed alloy. The faster creep rates in the processed alloy than in the same alloy in an unprocessed state may be explained in terms of enhanced diffusivity in non-equilibrium grain boundaries, by the increase in the rate of dislocation storage at grain boundaries, faster recovery of grain boundaries and by the direct contribution of grain boundary sliding to creep strain. 


\section{Acknowledgments}

This work was supported by the Czech Science Foundation under grant No. P108/11/2260. EBSD measurements were done by RNDr. Ales Jäger, Ph.D. of the Institute of Physics ASCR, Prague.

\section{References}

[1] R.Z. Valiev, T.G. Langdon, Prog. Mater. Sci. 51, 881 (2006).

[2] Y. Zhu, R.Z. Valiev, T.G. Langdon, N. Tsuji, K. Lu, MRS Bull. 35, 977 (2010).

[3] V.F. Terentyev, S.V. Dobatkin, S.A. Nikulin, V.I. Kopylov, D.V. Prosvirnin, S.O. Rogachev, I.O. Bannykh, Kovove Mater. 49, 65 (2011).

[4] F.R.N. Nabarro, Reports of a Conference on Strength of Solids, The Physical Society, London 1948, p. 75.

[5] C. Herring, J. Appl. Phys. 221, 437 (1950).

[6] R.L. Coble, J. Appl. Phys. 34, 1679 (1963).

[7] I. Charit, K.L. Murty, J. Nucl. Mater. 374, 354 (2008).

[8] M. Pahutová, J. Čadek, V. Černý, J. Nucl. Mater. 61, 285 (1976).

[9] M. Pahutová, K. Kuchařová, J. Čadek, J. Nucl. Mater. 131, 20 (1985).
[10] R. Kishore, J. Nucl. Mater. 385, 591 (2009).

[11] W. Li, R.A. Holt, J. Nucl. Mater. 401, 25 (2010).

[12] T.A. Hayes, M.E. Kassner, R.S. Rosen, Metall. Mater. Trans. A 33, 337 (2002).

[13] J. Čadek, Creep in Metallic Materials, Elsevier Science Publisher, Amsterdam 1988.

[14] T.G. Langdon, Acta Metall. Mater. 42, 2437 (1994).

[15] H.G. Kim, Y.H. Kim, B.K. Choi, Y.H. Jeong, J. Nucl. Mater. 359, 268 (2006).

[16] R. Lagneborg, Scr. Met. 7, 605 (1994).

[17] P.M. Sargeant, M.F. Ashby, Scr. Met. 16, 1414 (1982).

[18] Y. Amoyal, S.V. Divinski, L. Klinger, E. Rabkin, Acta Mater. 56, 5500 (2008).

[19] A.H. Chokshi, Mater. Sci. Eng. A 483-484, 485 (2008).

[20] M. Kawasaki, I.J. Beyerlein, S.V. Vogel, T.G. Langdon, Acta Mater. 56, 2307 (2008).

[21] M. Kawasaki, V. Sklenicka, T.G. Langdon, J. Mater. Sci. 45, 271 (2010).

[22] M. Kvapilova, V. Sklenicka, J. Dvorak, P. Kral, Key Eng. Mater. 465, 382 (2011).

[23] M. Kawasaki, V. Sklenicka, T.G. Langdon, Kovove Mater. 49, 75 (2011). 